\title{
Perception of surgical complications among patients, nurses and physicians: a prospective cross-sectional survey
}

\author{
Ksenija Slankamenac ${ }^{1}$, Rolf Graf ${ }^{1}$, Milo A Puhan ${ }^{2,3+}$ and Pierre-Alain Clavien ${ }^{1 *+}$
}

\begin{abstract}
Background: Several scores grade the severity of post-operative complications but it is unclear whether such scores truly reflect the perception of patients and practicing nurses and physicians.
\end{abstract}

Study Design: 227 patients, 143 nurses and 245 physicians independently rated the severity of 30 common postoperative complications on a numerical analogue scale from 0 (not severe at all) to 100 (extremely severe) while being blinded towards the Clavien-Dindo classification. We considered a difference in ratings of $>10$ to be clinically important in distinguishing between grades of severity and groups. We evaluated the level of reproducibility of responses by calculating intraclass correlation coefficients (ICC) and compared scores across severity grades and between groups using the generalized estimating equations.

Results: Reproducibility of the ratings was good for all three groups (ICCpatients 0.71 (95\%-Cl 0.64-0.76), ICCnurses $0.83(0.78-0.87)$ and ICCphysicians 0.87 (0.83-0.90)). The participants' perceptions of the severity of complications reflected the Clavien-Dindo classification (median of grade I: 20 (IQR 10-30), grade II: 40 (31.3-52.5), grade IIla: 50 (40-60), grade IIIb: 70 (60-75), grade IVa: 85 (80-90) and grade IVB: 95 (90-100)). Although patients' perception differed significantly from those of physicians (average difference $-8.7(95 \%-\mathrm{Cl}-10.4$ to $-6.9, \mathrm{p}<0.001)$ and nurses (difference $-2.8(-4.8$ to $-0.8, p=0.007)$ they did not reach our thresholds for clinical importance.

Conclusions: The severity of post-operative complications is perceived similarly by patients, nurses and physicians and reflects the Clavien-Dindo classification well. Our results support the use of Clavien-Dindo classification system as part of the shared or informed decision making process.

Keywords: Perception, surgical complications, patients, nurses and physicians

\section{Introduction}

A well-known editorial in the Lancet highlighted the poor methodology and lack of convincing outcome measures in most surgical studies [1]. Mortality and a variety of markers for morbidity are commonly used but there is an ongoing debate on how to define and standardize post-operative complications. This is well illustrated by a systematic review that found more than 40 different definitions of anastomotic leaks in 107 different studies [2]. Additionally, terms such as major, severe or

\footnotetext{
* Correspondence: clavien@access.uzh.ch

† Contributed equally

${ }^{1}$ Department of Surgery, University Hospital Zurich, Switzerland

Full list of author information is available at the end of the article
}

minor complications were used in an inconsistent manner, often without any explicit definition.

A group of surgeons, epidemiologists, and statisticians recognized these shortcomings and published a series of articles [3-5]. In 1992, Clavien et al proposed new definitions for post-operative complications, and a classification system to grade complications by severity based on the type and invasiveness of the treatment needed to treat a complication [6]. In 2004, a revised version of the classification system was proposed, based on the same principle, but eliminating criteria such as length of hospital stay [7]. This revised Clavien-Dindo classification classifies post-operative complications from grade I to $\mathrm{V}$ according to their need for more or less invasive treatment [7].

\section{C) Biomed Central}


However, all attempts to classify postoperative complications were developed by experts without taking the perspective of patients and practising health care professionals into consideration. If the perception of the severity of postoperative complication is weakly associated with a classification system its use in research and practice seems to be of limited value. In turn, if a classification system reflects the perspective of patients and health care professionals there would be opportunities to use the classification system for research but also to explain potential risks for post-operative morbidity to patients and, thereby, to support the decision making process. In the absence of evidence in the literature we assessed how patients, nurses and physicians perceive the severity of post-operative complications and how strongly their perception is associated with the ClavienDindo classification system for post-operative complications.

\section{Materials and methods}

\section{Study design, Population}

We conducted a prospectively planned cross-sectional study and included physicians, nurses and patients between January 21 and December 20, 2009. We invited patients scheduled for elective minor or major abdominal surgery with any underlying disease at a single tertiary care centre (Department of Visceral and Transplantation Surgery, University Hospital of Zurich, Switzerland). Further inclusion criteria were capacity to act without legal guardian and spoken and written German as the daily language. Patients were excluded if they had cognitive difficulties and diseases, which may result in unreliable answers, and if they were unable to read and/or write. We recruited eligible patients giving informed consent from the inpatient clinic completing the questionnaires once before surgery a well as from the outpatient clinic completing the questionnaire twice in order to assess its reproducibility (Figure 1).

We recruited nurses and physicians from surgical departments (visceral surgery, general surgery, traumatology and urology) and disciplines closely related to surgery (anesthesia and surgical intensive care units). We also sent the questionnaire to heads of surgical departments of 63 hospitals in the German-speaking part of Switzerland, 29 hospitals in Germany and 4 hospitals in Austria and invited them to participate voluntarily and anonymously with their surgical teams in this survey. Since it was not possible to retrieve the exact number of nurses and surgeons in those teams we could not calculate the response rate in nurses and physicians.

The study was approved by the institutional review board of Zurich (Switzerland) for human studies and internationally registered at clinicaltrials.gov (NCT 00785096).

\section{Development of the questionnaire}

We first identified a total of 161 post-operative complications in abdominal surgery from our prospectively managed database and the literature [8-10]. Five board certified senior staff surgeons checked the list for completeness and estimated independently the frequency as well as the relevance of these complications on a Likerttype scale from 1 (very infrequent respectively not relevant) to 6 (very frequent respectively very relevant). In order to select the five most frequent and most relevant complications within each complication grade of the Clavien-Dindo classification (grades I, II, IIIa, IIIB, IVa and $\mathrm{IVb}$, see below) we multiplied the frequency by the relevance for each complication and selected those five complications with the highest product within each complication grade (I to IVB). This approach resulted in 30 post-operative complication scenarios representing the most relevant and most frequent complications. Some complications appeared repeatedly due to different therapeutic consequences (e.g. re-operation due to anastomotic insufficiency [grade IIIb] and multi-organ failure due to anastomotic insufficiency [grade IVb]). Each of the 30 clinical scenarios described the complications themselves, what patients may feel when having these complications, the adequate therapy to treat the complications and its consequences on the length of hospital stay and future health outcomes. The questionnaire did not comment on the health state after (partial) recovery or on the course of recuperation after the hospital stay. The questionnaire was not disease-or and surgery-specific and, therefore, applicable to any patient planned for abdominal surgery. The content of the questionnaire was identical for patients, physicians and nurses but adapted to appropriate terminology so that the scenarios were easily understandable for all three groups. The questionnaire required about 30 minutes to complete. The full questionnaire is available from the authors on request.

We also developed a numerical answer scale from 0 (not severe at all) to 100 (extremely severe) to estimate the severity of post-operative complications. Numerical answer scales with numbered intervals and anchors are known to yield the most reliable answers and to require the shortest time for completion as compared with other scales (e.g. visual analogue scale) [11-21].

In cognitive debriefings, fifteen volunteers (five from each group) completed the draft questionnaire and were interviewed for completeness and comprehensibility of the 30 scenarios. Based on this feedback we made minor changes in wording and completed the final version of the questionnaire.

\section{The Clavien-Dindo classification of post-operative complications}

The Clavien-Dindo classification [7] is a widely used therapy-oriented classification system and classifies post- 


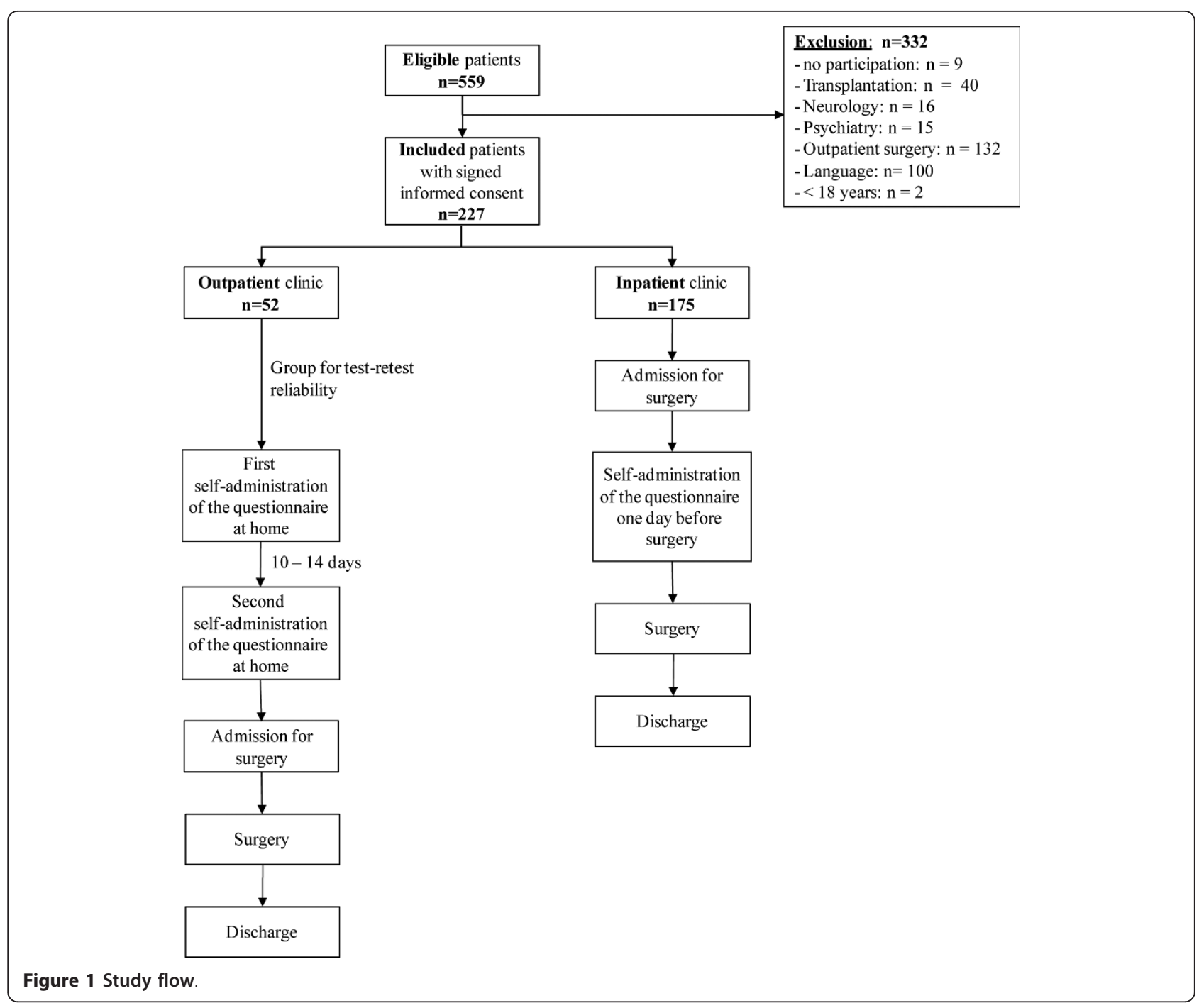

operative complications from grade I to $\mathrm{V}$ according to their need for treatment. A grade I complication is any deviation from the normal postoperative course without the need of further treatment. A grade II complication requires a pharmacological treatment. A grade III complication requires surgical intervention under local (grade IIIa) or under general anesthesia (grade IIIb). A patient with a grade IV complication has a life-threatening complication and requires ICU management. Grade V means the death of a patient. This Clavien-Dindo classification has currently been used in more than 350 studies from various surgical fields [22-28] and was also proposed as a possible gold standard to assess post-operative complications [4].

\section{Sample size}

There are no standard rules to estimate required sample sizes for the validation of patient-, nurses and physiciansreported outcomes. To estimate sample size requirements for reproducibility (test-retest reliability) we expected an intraclass correlation coefficient (ICC) of 0.7 to indicate sufficient test retest reliability. To estimate the ICCs with good precision (95\% confidence interval width of \pm 0.1 ), we calculated we needed to include data from 52 patients, 52 nurses and 52 physicians [29]. This group size would be large enough to detect a difference of 5 points on the 0 to 100 rating scale, which we considered to be of potential clinical relevance to distinguish between grades and groups of participants. Assuming a standard deviation of 12.5 , based on a pilot study [23], we needed 219 participants in each group (patient, nurses and physicians) to have a power of $80 \%$ at a significance level of 0.05 while expecting a drop out rate of $15 \%$.

\section{Statistical Analyses}

Our database did not have any missing values since we paid considerable attention to a complete collection of 
data. In a first step, we expressed the distribution of ratings using means and standard deviation or medians and interquartile ranges.

We calculated ICCs to assess the reproducibility of the ratings. We considered ICCs of 0.7 or higher to be sufficient to proceed with the main analysis. In the main analysis, we used generalized estimating equations (GEE) to compare whether ratings differed between severity grades (I to IVb) and between patients, nurses and physicians. We used GEE to take the clustered structure of our data into consideration, as every respondent rated each of the 30 scenarios. A statistical model not considering the clustered structure would lead to an underestimation of standard errors. Because of our large sample size small differences could be statistically significant but of little clinical relevance. Therefore, we also determined, before conducting the analyses, a difference of 5 points or lower in average rating to be clinically non-important in distinguishing between grades of severity and groups. We considered a difference between 5 and 10 to be of potential importance, one that would need further investigation, and a difference of more than 10 to be clinically important. We conducted all analyses using STATA (version 10, Stata Corp., College Station, Texas).

\section{Results}

\section{Participants}

During the study period, 559 patients were assessed for eligibility. Three hundred and thirty-two patients were not eligible and 227 patients gave the full consent for the study (Figure 1). One hundred and seventy-five patients completed the questionnaire, of which 52 patients completed the questionnaire twice before surgery for testing reproducibility (Figure 1). Two hundred patients had minor or major abdominal surgery whereas 27 patients (11.9\%) suffered from a disease which did not require surgery or could not be operated due to different reasons such as age, the presence of risk factors (e.g. major cardiac disease) or some patients denied further surgical treatment.

Patient characteristics and further intra-operative results are summarized in Table 1. Almost a third of the patients (73 of 227 patients) already had at least one post-operative complication in their medical history. Post-operative outcomes will be reported in detail elsewhere.

Despite four written reminders and requests for voluntary and anonymous participation, only 143 nurses participated in the study (Table 2). Fifty-two of the 143 nurses completed the questionnaire twice for evaluating reproducibility. The time period between the first and second survey varied between five days (minimum) and eight weeks (maximum). In addition, 245 physicians (Table 2) participated in the study, of which 52 completed the questionnaire twice.
Table 1 Patients' characteristics, intra-operative parameters and post-operative outcome

\begin{tabular}{|c|c|}
\hline Patients' characteristics & Patients $(n=227)$ \\
\hline Age (years) & $54(41-66)$ \\
\hline Gender, male/female (\%) & 116/111 (51.1\%/48.9\%) \\
\hline ASA score & $2(2-3)$ \\
\hline$-\leq 2$ & $149(65.6 \%)$ \\
\hline$->2$ & 78 (34.4\%) \\
\hline Nutrition risk score & $1(0-2)$ \\
\hline$-<3$ & 189 (83.3\%) \\
\hline$-\geq 3$ & $38(16.7 \%)$ \\
\hline Benign/malign disease (\%) & $153 / 74(67.4 \% / 32.6 \%)$ \\
\hline Pre-operative chemotherapy (\%) & $31(13.7 \%)$ \\
\hline Pre-operative radiotherapy (\%) & $19(8.4 \%)$ \\
\hline Body mass index $\left(\mathrm{kg} / \mathrm{m}^{2}\right)$ & $25.5(22.1-31.6)$ \\
\hline Intra-operative parameters & Patients $(n=200)$ \\
\hline Minor/major surgery (\%) & 133/67 (66.5\%/33.5\%) \\
\hline Surgery time (minutes) & $120(83.8-200)$ \\
\hline Blood transfusion (\%) & $4(2 \%)$ \\
\hline Blood loss (mL) & $20(5-100)$ \\
\hline Post-operative outcome & Patients $(n=200)$ \\
\hline Length of hospital stay (days) & $7(4-9)$ \\
\hline Intensive care unit stay (\%) & $33(16.3 \%)$ \\
\hline Intensive care unit stay (days) & $0(0-1)$ \\
\hline Mortality (\%) & $0 \%$ \\
\hline Morbidity (\%) & $107(53.5 \%)$ \\
\hline
\end{tabular}

All results in median and interquartile range (IQR)

ASA = American Society of Anesthesiologists

\section{Reproducibility of the questionnaire}

Reproducibility of the ratings was good for all three groups: ICCpatients 0.71 (95\% CI: 0.64 to 0.76), ICCnurses 0.83 ( $95 \% \mathrm{CI}: 0.78$ to 0.87 and ICCphysicians 0.87 (95\% CI: 0.83 to 0.90$)$ ).

Perception of the severity of post-operative complications The median severity rating of the 30 complication scenarios differed, from 10 (IQR 5-17.5) to 95 (IQR 90100). Median ratings from scenarios in grade I varied from 10 to 30 (IQR 5-40), in grade II ratings from 35 to 50 (IQR 25-60) and in grade IIIa from 40 to 60 (IQR 30-70). With an increase in severity of the complications ( $\geq$ grade IIIb) we observed less variation in median and IQR but still an increase in severity from grade to grade according to the Clavien-Dindo classification (Table 3).

\section{Association of the patients' and health care professional perception with the Clavien-Dindo classification}

The perception of the severity of post-operative complications of all participants (patients, nurses and physicians) increased with the severity in the Clavien-Dindo 
Table 2 Nurses' and physicians' characteristics

\begin{tabular}{|c|c|}
\hline & Nurses $(n=143)$ \\
\hline Gender, male/female (\%) & 29/114 (20.3\%/79.7\%) \\
\hline Years on the job & $12(1-41)$ \\
\hline \multicolumn{2}{|l|}{ Specialization } \\
\hline - abdominal surgery & 57 (39.8\%) \\
\hline - intensive care unit & 27 (18.9\%) \\
\hline - emergency & $24(16.8 \%)$ \\
\hline - cardiac/vascular & $18(12.6 \%)$ \\
\hline \multirow[t]{2}{*}{ - others } & $17(11.7 \%)$ \\
\hline & Physicians $(n=245$ ) \\
\hline Gender, male/female (\%) & $167 / 78(68.2 \% / 31.8 \%)$ \\
\hline Years on the job & $9(4-18)$ \\
\hline \multicolumn{2}{|l|}{ Country } \\
\hline - Switzerland & $192(78.4 \%)$ \\
\hline - Germany & $38(15.5 \%)$ \\
\hline - Austria & $15(6.1 \%)$ \\
\hline \multicolumn{2}{|l|}{ Position } \\
\hline - resident & $114(46.5 \%)$ \\
\hline - chief resident & $8(3.3 \%)$ \\
\hline - junior attending surgeon & $68(27.8 \%)$ \\
\hline - senior attending surgeon & $27(11.0 \%)$ \\
\hline - chief of service & $28(11.4 \%)$ \\
\hline \multicolumn{2}{|l|}{ Specialization } \\
\hline - general surgery & $94(38.4 \%)$ \\
\hline - abdominal surgery & $79(32.2 \%)$ \\
\hline - anesthesia & $23(9.4 \%)$ \\
\hline - cardiac/vascular & $10(4.1 \%)$ \\
\hline - others & $39(15.9 \%)$ \\
\hline
\end{tabular}

All results in median and interquartile range (IQR)

Others in nurses = anesthesia, traumatology, thoracic surgery and operating room nurses

Others in physicians = internal medicine, urology, gynecology, thoracic surgery, traumatology, gastroenterology, orthopedic and pediatric surgery

classification (Figure 2). The ratings of all scenarios except for two (wound infections according to the grade IIIa and IIIb) matched with what would be expected from the Clavien-Dindo classification. Participants estimated the severity of a grade I complication with a median of 20 (IQR 10-30), grade II with a median of 40 (IQR 31.3-52.5), grade IIIA with a median of 50 (IQR 40-60), grade IIIB with a median of 70 (IQR 60-75), grade IVA with a median of 85 (IQR $80-90$ ) and grade IVB complications with a median of 95 (IQR 90-100). Patients, nurses and physicians graded the complication scenarios similarly across all grades of the ClavienDindo classification (I to IVb) (Figure 3).

\section{Participants' perception of post-operative complications}

Despite statistical significance, patients estimated the severity of post-operative complications similar to physicians with a difference that was below our a priori defined threshold for clinical relevance of $>10$ (unadjusted difference -8.7, 95\%-confidence interval (CI) -10.4 to $-6.9, \mathrm{p}<0.001$ ) and nurses (unadjusted difference $-2.8,95 \%-\mathrm{CI}-4.8$ to $-0.8, \mathrm{p}=0.007)$. Also, there was a statistically significant difference between the estimation of the severity between physicians and nurses (difference $-5.9,95 \%-C I-7.9$ to $-3.9, \mathrm{p}<0.001$ ), which, however, did not exceed the threshold for clinical relevance.

\section{Discussion}

Our study showed that the perception of the severity of post-operative complications can be measured reliably and that it closely reflects the Clavien-Dindo classification. Although the patients' perception differed statistically significantly from those of physicians and nurses we do not consider these differences to be clinically relevant.

For the first time a large number of patients, nurses and physicians estimated the perceived severity of the same complications. We compared these perceptions with a widely used classification system that was developed, based on the experience and knowledge of expert surgeons [2,7]. Although systems such as the ClavienDindo classifications system seemed to reduce uncertainty about how to define post-operative complications, the validity of this classification system was never evaluated from the perspective of patients and health care professionals. Notably, not only health care professionals but also patients classified the severity of complications according to the need for treatment and identically to the Clavien-Dindo classification. This is illustrated by the scenarios that refer to identical complications (e.g. anastomotic insufficiency, wound infection or ulcer) but different therapeutic consequences. We could also show that nurses, who often have a closer relationship with patients than physicians, perceive the severity of complications between that of physicians and patients, a result that is not unexpected.

The similarity in the perception of post-operative complications by patients and health care professionals indicate that they share a common basis, which could be valuable for decision making. Today, surgeons mainly explain the frequency of post-operative complications to patients without explaining their severity. Frequencies of possible post-operative complications are important but patients will be better informed if they also know their severity. Our study indicates that the Clavien-Dindo classification system could be used as the basis for an improved explanation to the patient, allowing the patient to better understand complications and their therapeutic consequences. This may greatly support the patients' decision for the proposed surgical treatment or alternatives. Since nurses share a similar perception about post-operative complications they may also get 
Table 3 Perception of the severity of post-operative complications

\begin{tabular}{|c|c|c|c|c|}
\hline Complication & Treatment & Grade & Median & $\begin{array}{l}\text { Interquartile } \\
\text { range }\end{array}$ \\
\hline Hypopotassemia & oral substitution of potassium & I & 10 & $5-17.5$ \\
\hline Oedema & diuretics & I & 15 & $10-25$ \\
\hline Dystelectasis & breath-physiotherapy & I & 20 & $10-30$ \\
\hline $\begin{array}{l}\text { Postoperative nausea and } \\
\text { vomiting }\end{array}$ & antiemetics & । & 20 & $10-30$ \\
\hline Wound infection & wound opened at the bedside, secondary wound healing & । & 30 & $20-40$ \\
\hline Local infection & antibiotics & $\|$ & 35 & $25-50$ \\
\hline Arrhythmia & medical treatment (e.g. beta-blockers) & $\|$ & 40 & $30-55$ \\
\hline Subileus & gastric tube, procinetics, antiemetics & $\|$ & 45 & $30-60$ \\
\hline Gastroparesis & gastric tube, procinetics, antiemetics & $\|$ & 45 & $30-60$ \\
\hline $\begin{array}{l}\text { Upper Gl-bleeding due to } \\
\text { ulcer }\end{array}$ & medical treatment (e.g. PPI), blood substitution & $\|$ & 50 & $35-60$ \\
\hline Wound infection & wound closure in local anesthesia & IIla & 40 & $30-50$ \\
\hline Pneumothorax & thoracic drain in local anesthesia & IIla & 50 & $40-60$ \\
\hline $\begin{array}{l}\text { Upper Gl-bleeding due to } \\
\text { ulcer }\end{array}$ & $\begin{array}{l}\text { gastroscopy with local treatment of the ulcer bleeding, medical treatment (e.g. } \\
\text { PPI), blood substitution }\end{array}$ & IIla & 50 & $40-65$ \\
\hline Intra-abdominal abscess & drainage & IIla & 57.5 & $40-70$ \\
\hline Deep venous thrombosis & lyses & IIla & 60 & $50-70$ \\
\hline Wound infection & wound closure in full anesthesia & $\mathrm{IIl \textrm {b }}$ & 40 & $30-55$ \\
\hline $\begin{array}{l}\text { Post-operative acute } \\
\text { bleeding }\end{array}$ & blood substitution, surgical revision & $11 \mathrm{lb}$ & 70 & $60-80$ \\
\hline Infected bilioma & surgical revision & IIlb & 70 & $60-80$ \\
\hline Anastomotic insufficiency & surgical revision, re-anastomoses & $\mathrm{lllb}$ & 70 & $60-80$ \\
\hline Mechanical ileus & surgical remove of adhesions & IIIb & 70 & $55-80$ \\
\hline Delirium & medicaments, intubation & $\mathrm{IVa}$ & 80 & $70-90$ \\
\hline Lung emboli & anticoagulation, intubation & $\mathrm{IVa}$ & 80 & $70-90$ \\
\hline Acute liver failure & medical substitution, ICU support & $\mathrm{IVa}$ & 85 & $75-90$ \\
\hline Acute renal failure & hemofiltration, ICU support & $\mathrm{IVa}$ & 85 & $75-90$ \\
\hline Anastomotic insufficiency & antibiotics, surgical revision, hemodynamic stabilization on the ICU & IVa & 90 & $80-97.5$ \\
\hline Low output syndrome & hemodynamic stabilization, hemofiltration & IVb & 90 & $80-100$ \\
\hline $\begin{array}{l}\text { Post-operative acute } \\
\text { bleeding }\end{array}$ & blood substitution, surgical revision, hemodynamic stabilization, hemofiltration & $\mathrm{IVb}$ & 90 & $80-100$ \\
\hline Colon ischemia & antibiotics, colon resection, hemodynamic stabilization, hemofiltration & $\mathrm{IVb}$ & 95 & $90-100$ \\
\hline ARDS & intubation, hemodynamic stabilization & $\mathrm{IVb}$ & 95 & $85.6-100$ \\
\hline Anastomotic insufficiency & antibiotics surgical revision, hemodynamic stabilization, hemofiltration & $\mathrm{IVb}$ & 95 & $90-100$ \\
\hline
\end{tabular}

Local infection was defined e.g. as central venous infection; PPI = proton-pump-inhibition treatment; ARDS = Acute respiratory distress syndrome

involved in the decision making process as equally important partners within the medical team.

\section{Strengths and limitations}

The large sample size of 615 participants and the three different groups (patients, nurses and physicians) strengthened the results of this study. Moreover, we had no missing values, neither in the answers of the questionnaire nor in other ratings. However, we were not able to reach the planned sample size of 219 nurses. In order to avoid any circularity, this is that respondents were aware of the Clavien-Dindo classification for each vignette and would, therefore had made matching ratings, patients, physicians and nurses were blinded and also unaware of the Clavien-Dindo classification. Only twenty-five surgeons (out of 245) knew the ClavienDindo classification because they were from our surgical department but they were also blinded for our classification of each vignette.

Our study had also some potential limitations. Each complication scenario described a single complication and its consequences but we did not take into account that quite commonly more than one complication may occur. Further studies will need to assess how patients 

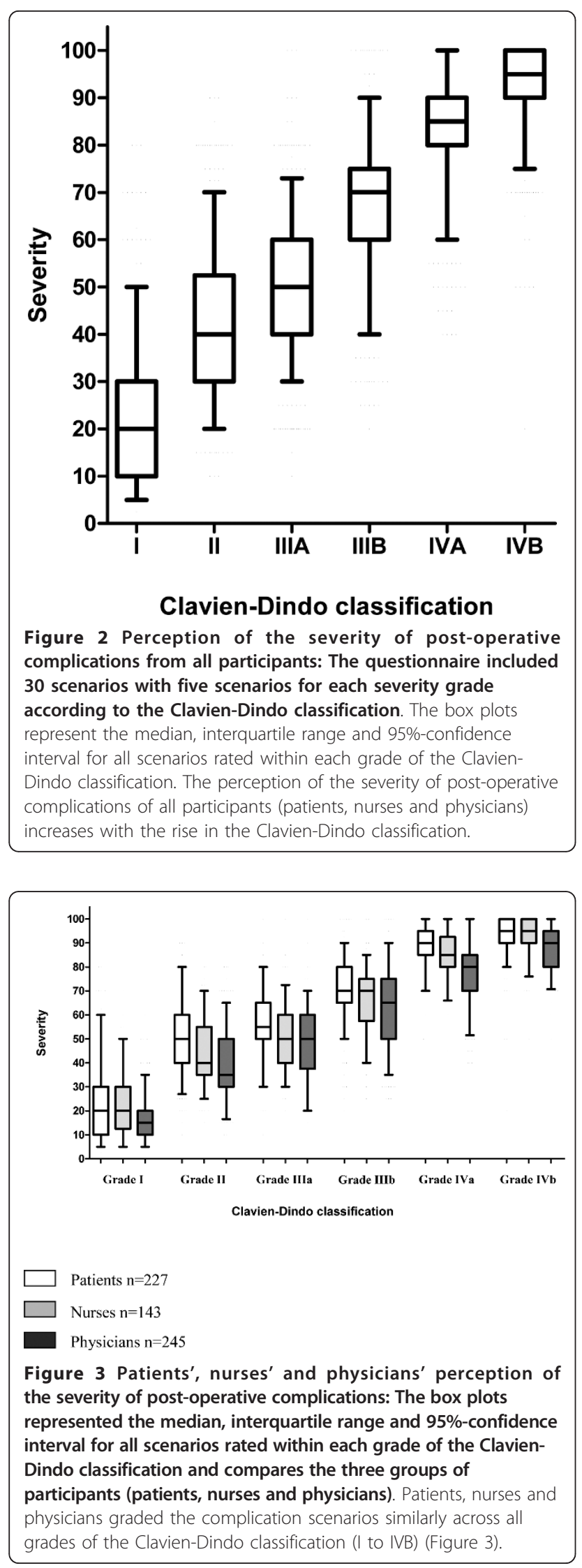

and health care professionals perceive multiple complications. Although we included a broad sample of participants, a possible selection bias could be that all our participants were from a university hospital. Participants from peripheral hospitals may grade the severity of post-operative complications differently. Further studies will also be needed on this topic.

\section{Conclusion}

In conclusion, the perception of post-operative complications estimated by patients, nurses and physicians was similar and associated with the Clavien-Dindo complication classification. Our results lend support to the use of this classification system as part of the shared or informed decision making process.

\section{Abbreviations}

ICC: intraclass correlation coefficient; GEE; generalized estimating equation; 95\% Cl; 95\% confidence interval; IQR: interquartile range; ASA: American Society of Anesthesiologists; PPI: proton-pump-inhibition treatment; ARDS: acute respiratory distress syndrome.

\section{Author details}

'Department of Surgery, University Hospital Zurich, Switzerland. ${ }^{2}$ Horten Center for Patient Oriented Research, University Hospital Zurich, Switzerland. ${ }^{3}$ Department of Epidemiology, Johns Hopkins Bloomberg School of Public Health, Baltimore, USA.

\section{Authors' contributions}

KS has made substantial contributions to conception and design, acquisition of data, analysis and interpretation of data. Furthermore KS has been involved in drafting the manuscript, revising it critically for important intellectual content and has given final approval of the version to be published.

RG has made substantial contributions to conception and design and interpretation of data: RG has been involved in revising it critically for important intellectual content and has given final approval of the version to be published.

MAP has made substantial contributions to conception and design, analysis and interpretation of data. Furthermore MAP has been involved in drafting the manuscript and revising it critically for important intellectual content. MAP has given final approval of the version to be published.

PAC has made substantial contributions to conception and design and interpretation of data. PAC has been involved in revising it critically for important intellectual content and has given final approval of the version to be published.

\section{Competing interests}

The authors declare that they have no competing interests.

Received: 22 September 2011 Accepted: 22 November 2011 Published: 22 November 2011

\section{References}

1. Horton R: Surgical research or comic opera: questions, but few answers. Lancet 1996, 347(9007):984-985.

2. Bruce J, Russell EM, Mollison J, Krukowski ZH: The measurement and monitoring of surgical adverse events. Health Technol Assess 2001, 5(22):1-194.

3. Barkun JS, Aronson JK, Feldman LS, Maddern GJ, Strasberg SM, Altman DG, Blazeby JM, Boutron IC, Campbell WB, Clavien PA, et al: Evaluation and stages of surgical innovations. Lancet 2009, 374(9695):1089-1096.

4. Ergina PL, Cook JA, Blazeby JM, Boutron I, Clavien PA, Reeves BC, Seiler CM, Altman DG, Aronson JK, Barkun JS, et al: Challenges in evaluating surgical innovation. Lancet 2009, 374(9695):1097-1104. 
5. McCulloch P, Altman DG, Campbell WB, Flum DR, Glasziou P, Marshall JC, Nicholl J, Aronson JK, Barkun JS, Blazeby JM, et al: No surgical innovation without evaluation: the IDEAL recommendations. Lancet 2009, 374(9695):1105-1112.

6. Clavien PA, Sanabria JR, Strasberg SM: Proposed classification of complications of surgery with examples of utility in cholecystectomy. Surgery 1992, 111(5):518-526.

7. Dindo D, Demartines N, Clavien PA: Classification of surgical complications: a new proposal with evaluation in a cohort of 6336 patients and results of a survey. Ann Surg 2004, 240(2):205-213.

8. Dimick JB, Chen SL, Taheri PA, Henderson WG, Khuri SF, Campbell DA Jr: Hospital costs associated with surgical complications: a report from the private-sector National Surgical Quality Improvement Program. J Am Coll Surg 2004, 199(4):531-537.

9. Fleischmann KE, Goldman L, Young B, Lee TH: Association between cardiac and noncardiac complications in patients undergoing noncardiac surgery: outcomes and effects on length of stay. Am J Med 2003, 115(7):515-520

10. Khan NA, Quan H, Bugar JM, Lemaire JB, Brant R, Ghali WA: Association of postoperative complications with hospital costs and length of stay in a tertiary care center. J Gen Intern Med 2006, 21(2):177-180.

11. Huskisson EC: Measurement of pain. Lancet 1974, 2(7889):1127-1131.

12. Huskisson EC: Measurement of pain. J Rheumatol 1982, 9(5):768-769.

13. Pincus T, Bergman M, Sokka T, Roth J, Swearingen C, Yazici Y: Visual Analog Scales in Formats Other than a 10 Centimeter Horizontal Line to Assess Pain and Other Clinical Data. J Rheumatol 2008, 35(8):1550-8.

14. Pincus $T$, Swearingen $C$, Wolfe $F$ : Toward a multidimensional Health Assessment Questionnaire (MDHAQ): assessment of advanced activities of daily living and psychological status in the patient-friendly health assessment questionnaire format. Arthritis Rheum 1999, 42(10):2220-2230

15. Wolfe F, Michaud K, Pincus T: Preliminary evaluation of a visual analog function scale for use in rheumatoid arthritis. J Rheumatol 2005, 32(7):1261-1266

16. Fries JF, Spitz P, Kraines RG, Holman HR: Measurement of patient outcome in arthritis. Arthritis Rheum 1980, 23(2):137-145.

17. Sriwatanakul K, Kelvie W, Lasagna L, Calimlim JF, Weis OF, Mehta G: Studies with different types of visual analog scales for measurement of pain. Clin Pharmacol Ther 1983, 34(2):234-239.

18. Grant S, Aitchison T, Henderson E, Christie J, Zare S, McMurray J, Dargie H: A comparison of the reproducibility and the sensitivity to change of visual analogue scales, Borg scales, and Likert scales in normal subjects during submaximal exercise. Chest 1999, 116(5):1208-1217.

19. Paul-Dauphin A, Guillemin F, Virion JM, Briancon S: Bias and precision in visual analogue scales: a randomized controlled trial. Am J Epidemiol 1999, 150(10):1117-1127.

20. Scott J, Huskisson EC: Graphic representation of pain. Pain 1976, 2(2):175-184.

21. Scott J, Huskisson EC: Vertical or horizontal visual analogue scales. Ann Rheum Dis 1979, 38(6):560..

22. Chun YS, Vauthey JN, Ribero D, Donadon M, Mullen JT, Eng C, Madoff DC Chang DZ, Ho L, Kopetz S, et al: Systemic chemotherapy and two-stage hepatectomy for extensive bilateral colorectal liver metastases: perioperative safety and survival. J Gastrointest Surg 2007, 11(11):1498-1504, discussion 1504-1495.

23. Clavien PA, Barkun J, de Oliveira ML, Vauthey JN, Dindo D, Schulick RD, de Santibanes E, Pekolj J, Slankamenac K, Bassi C, et al: The Clavien-Dindo classification of surgical complications: five-year experience. Ann Surg 2009, 250(2):187-196

24. de Santibanes E, Ardiles V, Gadano A, Palavecino M, Pekolj J, Ciardullo M: Liver transplantation: the last measure in the treatment of bile duct injuries. World J Surg 2008, 32(8):1714-1721.

25. Haynes AB, Weiser TG, Berry WR, Lipsitz SR, Breizat AH, Dellinger EP, Herbosa T, Joseph S, Kibatala PL, Lapitan MC, et al: A surgical safety checklist to reduce morbidity and mortality in a global population. $N$ Engl J Med 2009, 360(5):491-499.

26. Jaffe J, Stakhovsky O, Cathelineau X, Barret E, Vallancien G, Rozet F: Surgical outcomes for men undergoing laparoscopic radical prostatectomy after transurethral resection of the prostate. J Urol 2007, 178(2):483-487, discussion 487.
27. Permpongkosol S, Link RE, Su LM, Romero FR, Bagga HS, Pavlovich CP, Jarrett TW, Kavoussi LR: Complications of 2,775 urological laparoscopic procedures: 1993 to 2005. J Urol 2007, 177(2):580-585.

28. Sundaram CP, Martin GL, Guise A, Bernie J, Bargman V, Milgrom M, Shalhav A, Govani M, Goggins W: Complications after a 5-year experience with laparoscopic donor nephrectomy: the Indiana University experience. Surg Endosc 2007, 21(5):724-728.

29. Shoukri MM: Statistical Methods in Medical Research: Sample size requirements for the design of reliability study: review and new results. Stat Methods Med Res 2004, 13: 251-271.

doi:10.1186/1754-9493-5-30

Cite this article as: Slankamenac et al:: Perception of surgical complications among patients, nurses and physicians: a prospective cross-sectional survey. Patient Safety in Surgery 2011 5:30.

\section{Submit your next manuscript to BioMed Central and take full advantage of:}

- Convenient online submission

- Thorough peer review

- No space constraints or color figure charges

- Immediate publication on acceptance

- Inclusion in PubMed, CAS, Scopus and Google Scholar

- Research which is freely available for redistribution

Submit your manuscript at www.biomedcentral.com/submit
Biomed Central 